\title{
Relação pais e filhos: compreendendo o interjogo das relações parentais e coparentais
}

\section{Relationships between parents and children: understanding the interplay of the parental and coparental relations}

\author{
Elisangela Böing ${ }^{1}$ \\ Maria Aparecida Crepaldi ${ }^{1}$
}

\begin{abstract}
RESUMO
Pesquisas têm dedicado atenção aos estilos e práticas parentais e seus efeitos no desenvolvimento de crianças. A coparentalidade é definida pelo envolvimento conjunto e recíproco de ambos os pais na educação dos filhos. Neste artigo são delineadas relações entre estilos parentais e coparentalidade. Trata-se de estudo exploratório descritivo e correlacional com doze famílias biparentais, com pelo menos uma criança de cinco a sete anos de idade. Foram utilizados dois instrumentos: Escala da Relação Coparental (ERC) e Questionário de Dimensões e Estilos Parentais (QDEP). Utilizou-se estatística descritiva e correlacional, com o uso do pacote estatístico SPSS 18.0. A validação (endossamento) da parentalidade do parceiro apareceu como um fator importante para os estilos parentais. Quanto mais as mães referiram endossar a parentalidade dos esposos, mais elas mencionavam uso do estilo democrático-recíproco por eles. A validação por parte das mães se relacionou positivamente ao suporte coparental: quanto mais perceberam o suporte de seus esposos, mais endossaram a parentalidade deles. A sabotagem coparental, referida por eles, apresentou relações positivas com uso do estilo permissivo (falta de firmeza) em ambos. Destaca-se a relação entre falta de firmeza parental e uso de estratégias punitivas; e de ambos com a sabotagem coparental. O conjunto dos resultados permitiu o delineamento das relações entre a coparentalidade e estilos parentais e poderão subsidiar
\end{abstract}

DOI: $10.1590 / 0104-4060.44615$

1 Universidade Federal de Santa Catarina. Departamento de Psicologia. Florianópolis, Santa Catarina, Brasil. Campus Reitor João Davi Ferreira Lima - Trindade. CEP: 88040-900. E-mails: elisangelaboing@gmail.com; maria.crepaldi@gmail.com 
intervenções psicológicas e psicoeducativas promotoras do desenvolvimento das crianças e suas famílias, em diferentes contextos.

Palavras-chave: estilos parentais; coparentalidade; família.

\begin{abstract}
Research has shown the styles and parenting practices and their effects on the development of children. The coparenting is defined by the joint involvement and reciprocal of both parents in the education of children. This article highlights relationships between parenting styles and coparenting. It is about a descriptive and correlational exploratory study with twelve biparental families with a five to seven years old child, at least. Two instruments were used: the Coparenting Relationships Scale (CRS) and the Parenting Styles and Dimensions Questionnaire (PSDQ). A descriptive and correlational statistic was used by the SPSS 18.0 statistical package. Results had shown that validation (endorsement) of the partner's parenting appeared as a relevant factor in parenting styles. The more mothers reported to endorse the parenthood of their spouses, the more they mentioned the use of a democratic reciprocal style. The validation by mothers was positively related to coparental support: the more they realized the support of their husbands, the more they endorsed their parenting. The coparental sabotage had a positive relationship with the use of a permissive style (lack of firmness) for both. Noteworthy is the relationship between lack of parental firmness and the use of punitive strategies; and both with coparental sabotage. The overall results show the relationship between coparenting and parenting styles, and they can be used for psychological and psychoeducational interventions in promoting the development of children and their families in different contexts.
\end{abstract}

Keywords: parenting styles; coparenting; family.

\title{
Introdução
}

A temática da criação dos filhos tem sido constante no cotidiano das pessoas e na sociedade e vem sendo muito pesquisada nas últimas décadas. Diversos trabalhos têm dedicado atenção especial aos estilos e práticas parentais. (ALVARENGA; PICCININI, 2001; CARVALHO; GOMIDE, 2005; COSTA; TEIXEIRA; GOMES, 2000; WEBER et al., 2004). Utiliza-se o termo "estilos parentais" como relativo às formas com que os pais lidam com as questões de 
poder, hierarquia e apoio emocional na relação com os filhos. Os pais possuem determinados valores que querem ver desenvolvidos em seus filhos e esses embasam suas metas educativas. As práticas educativas parentais, por sua vez, correspondem a comportamentos definidos por conteúdos específicos. São estratégias usadas para suprimir comportamentos considerados inadequados ou incentivar a ocorrência de comportamentos desejados. Desta forma, o estilo e a prática educativa estão normalmente associados, uma vez que o conjunto de práticas educativas utilizadas pelos pais na interação com os filhos formará o estilo parental, ou seja, as práticas educativas, combinadas de diferentes formas, resultam em estilos parentais diversos. Os estilos parentais representam, portanto, o contexto em que os pais influenciam seus filhos através de suas práticas, de acordo com suas crenças e valores. São tendências relativamente estáveis através das quais os pais reagem com uma conduta (ou prática) dirigida à criança. A seleção das práticas educativas está guiada pelas metas, as quais são embasadas pelos valores parentais - os estilos parentais. (ALVARENGA; PICCININI, 2001; BEM; WAGNER, 2006; CARVALHO; GOMIDE, 2005; KOBARG; VIEIRA; VIEIRA, 2010; OLIVEIRA et al., 2002; PICCININI et al., 2007; WEBER et al., 2004; WEBER et al., 2006).

As práticas educativas parentais estão relacionadas aos problemas de comportamento que, em geral, são agrupados em duas categorias: os comportamentos de externalização (agressão verbal ou física; destruição de objetos; hiperatividade; comportamentos delinquentes) e os de internalização (isolamento social; ansiedade; depressão; queixas somáticas). (ACHENBACH, 1991; ALVARENGA; PICCININI, 2001; BORDIN; MARI; CAEIRO, 1995; CARVALHO; GOMIDE, 2005).

Embora haja indícios de que, já por volta dos três anos, algumas práticas parentais se relacionam a problemas de externalização da criança, é na fase da adolescência que esses comportamentos ficam mais evidentes e, portanto, são mais estudados. (MACARINI et al., 2010). Tremblay (2000) afirma que apenas nos últimos anos passou-se a considerar a relevância clínica dos indicadores de externalização apresentados por crianças com menos de seis anos como preditores de possíveis dificuldades futuras. Segundo o autor, os anos pré-escolares constituem um período crucial, durante o qual as crianças aprendem estratégias de substituição à agressão.

Em estudo longitudinal, Baumrind (1991) investigou o impacto dos estilos parentais no desenvolvimento de 139 crianças aos 15 anos de idade, as quais já haviam participado de outro estudo aos 04 e 10 anos de idade. Com base nas análises do estudo que contemplou as idades de 04 e 10 anos, a partir das duas dimensões do comportamento parental utilizadas nas revisões de Maccoby e Martin (1983) - controle e afeto - Baumrind derivou uma classificação de 
quatro tipos de comportamento parental: democrático-recíproco; autoritário; permissivo; e rejeitador-negligente. Estes quatro protótipos diferem em relação ao contexto social, ao período de desenvolvimento e ao método de acesso, mas assumem características específicas.

Pais com estilo democrático-recíproco possuem altos níveis de exigência e de responsividade; são assertivos, mas não intrusivos ou restritivos. Os pais de estilo autoritário possuem alta exigência e baixa responsividade (são pouco afetivos). Modelam, controlam e avaliam o comportamento da criança de acordo com regras de conduta estabelecidas através de padrões, em geral, absolutos. Enfatizam a obediência como uma virtude e são a favor de medidas punitivas para lidar com aspectos da criança que entram em conflito com o que eles pensam ser certo. Já os pais permissivos apresentam baixos níveis de exigência e altos níveis de afeto. Tentam se comportar de maneira não punitiva e receptiva diante dos desejos e ações da criança. Os pais com estilo rejeitador-negligente apresentam baixos níveis de exigência e de responsividade, mostram-se indiferentes. Demonstram pouco envolvimento com a tarefa de socialização da criança, não monitorando seu comportamento. Tendem a manter seus filhos à distância, respondendo somente às suas necessidades básicas, o que pode estar associado a algum tipo de maltrato. (BAUMRIND, 1966, 1991).

A coparentalidade, por sua vez, é definida pelo envolvimento conjunto e recíproco de ambos os pais na educação, formação e decisões sobre a vida de seus filhos. Tendo por base a perspectiva sistêmica de família, a relação coparental é compreendida como um subsistema, no mínimo, triádico (dois adultos cuidadores e uma criança), que apresenta características específicas que influenciam no desenvolvimento da criança e no sistema familiar em sua totalidade. Trata-se, portanto, de um subsistema autônomo que se inter-relaciona com os demais subsistemas familiares - tais como, conjugalidade e estilos parentais individuais. (BONDS; GONDOLI, 2007; FEINBERG, 2002, 2003; VAN EGEREN; HAWKINS, 2004).

A coparentalidade é compreendida como uma função que requer o desejo mútuo entre os cuidadores principais de proporcionar segurança, proteção, suporte emocional e físico das necessidades da criança ao longo do seu crescimento, independentemente do tipo de laço relacional. Refere-se, portanto, à forma como os pais coordenam as suas funções parentais, como se apoiam ou não, e como gerem os conflitos face à educação dos filhos. (FEINBERG, 2002, 2003). As quatro dimensões do subsistema coparental, identificadas por Feinberg (2002, 2003) em seu Modelo Ecológico da Coparentalidade, são: acordo ou desacordo nas práticas parentais; divisão do trabalho relacionado à criança; suporte/sabotagem da função coparental; e gestão conjunta das relações familiares. 
Na temática da criação dos filhos, entretanto, os estilos parentais mantêm-se como dimensões importantes relacionadas à coparentalidade. Abidin e Brunner (1995) mostraram que existe uma correlação positiva e significativa entre coparentalidade positiva e o estilo democrático-recíproco, em ambos os progenitores. E em seu Modelo Ecológico da Coparentalidade, Feinberg $(2002,2003)$ descreve que a coparentalidade positiva está relacionada com a competência parental percebida pelos progenitores, com o comportamento das crianças e adolescentes, com baixos níveis de stress e com uma parentalidade democrático-recíproca.

Neste contexto, o presente estudo buscou ampliar a compreensão da temática da criação dos filhos em uma perspectiva relacional-sistêmica, relacionando as variáveis dos estilos parentais de pais e de mães, de famílias biparentais com crianças de cinco a sete anos de idade, entre si (estilos materno e paterno) e destas com as variáveis da coparentalidade.

\section{Método}

Participaram do estudo doze famílias biparentais, com crianças de cinco a sete anos de idade, cujos pais (biológicos ou não) estavam vivendo juntos por um período mínimo de seis meses e que já haviam completado 18 anos quando do nascimento do filho mais velho. As famílias foram convidadas a participar do estudo através de cartas-convite enviadas às Instituições de Educação Infantil em uma cidade do sul do Brasil. O contato inicial com as famílias foi feito por telefone. Após o retorno das cartas-convite, a coleta de dados foi realizada na residência das famílias participantes, através de visitas domiciliares.

Os instrumentos utilizados foram:

Questionário de Dimensões e Estilos Parentais (QDEP). O Parenting Styles and Dimensions Questionnaire (PSDQ) - Short Form (ROBINSON et al., 2001) é uma escala do tipo Likert de cinco pontos $(1=$ Nunca; $5=$ Sempre), constituída por 32 itens, com coeficientes de $.86, .82$ e .64 para os estilos democrático-recíproco, autoritário e permissivo, respectivamente. O estilo democrático-recíproco (15 itens) está dividido em quatro subescalas: calor e envolvimento; estimulação do raciocínio; participação democrática; e paciência e respeito. O estilo autoritário também apresenta quatro subescalas: hostilidade verbal; castigos físicos; estratégias punitivas/sem explicar razões; e diretividade excessiva. $\mathrm{O}$ estilo permissivo apresenta duas subescalas: falta de firmeza e excesso ou falta de autoconfiança. Compreende uma versão "Mãe" e uma versão 
"Pai", constituídas pelos mesmos 32 itens. Na presente pesquisa utilizou-se a versão portuguesa (PEDRO; CARAPITO; RIBEIRO, 2015) em função das similaridades da cultura e da língua entre Brasil e Portugal.

Escala da Relação Coparental (ERC). A Coparenting Relationships Scale (CRS) é a medida de autorrelato mais recente, desenvolvida por Feinberg, Brown e Kan (2012), para avaliar a coparentalidade com base na Teoria Ecológica da Coparentalidade, do primeiro autor. (FEINGBERG, 2002, 2003). É composta por 35 itens cujas respostas variam numa escala de sete pontos $(0$ = não é verdadeiro sobre nós; 6 = muito verdadeiro sobre nós), com Alfas de Cronbach entre .91 e .94. (FEINBERG et al., 2012). É composta pelas subescalas: acordo coparental (4 itens); suporte coparental (6 itens); endossar a parentalidade do parceiro (7 itens); sabotagem coparental (6 itens); divisão do trabalho (2 itens); e proximidade coparental (5 itens).

\section{Resultados}

Foram realizadas análises correlacionais entre as diferentes dimensões dos estilos parentais dos pais e das mães (autorrelato e relato sobre o estilo parental do cônjuge) e as dimensões da coparentalidade (relato de ambos). Por se tratar de um número pequeno de participantes $(\mathrm{N}=24)$, utilizou-se a análise de correlação de Spearman ( $\rho$ de Spearman). Foram consideradas apenas as relações fortes (com coeficientes de correlação de 0,7 a 0,9 ) e moderadas (coeficientes de 0,4 a 0,6), com valores de $\mathrm{p}<0,05$. (DANCEY; REIDY, 2013). Os dados foram analisados por meio do Statistical Package of Social Sciences (SPSS versão 18.0). Vale esclarecer ainda que na descrição dos resultados o termo "pais" foi utilizado exclusivamente como plural de pai, nunca para designar o casal parental.

\section{Caracterização das famílias}

Participaram do estudo doze famílias (doze pais e doze mães). Os pais apresentaram idade média de 37,5 anos $(\mathrm{SD}=7,50)$ e as mães 34,8 anos $(\mathrm{SD}=7,1)$. Quanto às crianças focais, sete são meninos e cinco meninas, cuja média de idade é de 6,2 anos $(\mathrm{SD}=0,7)$. A média de anos de escolaridade dos pais é de $11,6(\mathrm{SD}=3,4)$; e das mães é de 13,9 anos $(\mathrm{SD}=2,8)$. Três casais apresentam o mesmo nível de escolaridade (pai e mãe entre si); um pai apresenta nível acima da esposa; e oito mães apresentam nível de escolaridade acima dos esposos. A 
média do total de rendimentos mensais dos pais é de $\mathrm{R} \$ 2.037,5(\mathrm{SD}=1.621,04)$; e das mães é de $\mathrm{R} \$ 1.239,09(\mathrm{SD}=602,00)$. A média aproximada da jornada de trabalho dos pais é de $38,7 \mathrm{~h}(\mathrm{SD}=6,0)$, e das mães é de 34,7 horas $(\mathrm{SD}=10,2)$. De acordo com o Critério de Classificação Econômica Brasileira (CCEB) da Associação Brasileira de Empresas de Pesquisa (ABEP, 2011), a maior parte das famílias pesquisadas pode ser considerada pertencente às classes econômicas B2 e B1, que apresentam, respectivamente, valores médios de renda familiar de $\mathrm{R} \$ 2.656,00$ e $\mathrm{R} \$ 4.754,00$.

\section{Estilos parentais}

Tanto as mães quanto os pais referiram uso do estilo democrático-recíproco, a respeito de si e do parceiro, em aproximadamente $75 \%$ das interações com a criança. Referiram uso do estilo autoritário em $25 \%$ das interações. Quanto ao uso do estilo permissivo, foi referido pelos pais (a respeito de si e das esposas) uso em, aproximadamente, $25 \%$ das interações; e na avaliação das mães a referência a este estilo é em torno de $25 \%$ com relação a si mesmas e um pouco menor na avaliação delas sobre os esposos: aproximadamente em $20 \%$ das interações deles com as crianças.

Embora haja uma predominância do uso do estilo democrático-recíproco, destaca-se que um estilo parental nunca é único ou homogêneo. Os resultados refletem uma porcentagem considerável de uso dos estilos autoritário e permissivo, cada um deles em, aproximadamente, um quarto das interações com as crianças. E mais do que caracterizar a predominância do estilo, a análise que será apresentada neste artigo buscou identificar as peculiaridades do uso dos diferentes estilos e quais os fatores relacionados a eles no interjogo das relações.

\section{Correlações entre os estilos parentais}

As análises entre os estilos parentais, segundo autoavaliação e avaliação do parceiro, indicaram fortes correlações entre a percepção dos pais a respeito de seu próprio estilo e do estilo de suas esposas. Quanto mais o pai refere fazer uso do estilo democrático, mais ele também faz esta referência a respeito da mãe $\left(, 750^{* *}, \mathrm{p}=0,005\right)$. Correlação semelhante ocorreu com o relato do pai sobre o estilo permissivo: quanto mais referiu estilo permissivo a respeito de si, mais referiu também este estilo com relação à sua esposa $\left(, 733^{* *}, p=0,007\right)$. Na percepção materna sobre si e sobre seu esposo, os estilos democrático-recíproco e permissivo não se relacionaram. Houve correlação apenas no estilo autoritário. Quanto mais a mãe referiu fazer uso de estilo autoritário, mais ela refere uso deste estilo pelo esposo $\left(, 830^{* *}, p=0,001\right)$. Contudo, quanto mais o pai referiu 
BÖING, E.; CREPALDI, M. A. Relação pais e filhos: compreendendo o interjogo das relações...

fazer uso do estilo autoritário, mais ele referiu o estilo permissivo em sua esposa $\left(, 723^{* *}, \mathrm{p}=0,008\right)$.

\section{Correlações entre os fatores do estilo democrático-recíproco}

No relato paterno, dentro do estilo democrático apareceram correlações fortes e positivas entre os fatores. Quanto mais calor/envolvimento o pai referiu sobre si, mais referiu também fazer uso da participação democrática $\left(, 870^{* *}, \mathrm{p}\right.$ $<0,001)$; e paciência/respeito $\left(, 937^{* *}, \mathrm{p}<0,001\right)$. E quanto mais ele referiu ter paciência/respeito no seu estilo, mais referiu uso da participação democrática $\left(, 805^{* *}, \mathrm{p}=0,002\right)$.

O calor/envolvimento do pai (em sua autoavaliação) também se relacionou positivamente com a sua avaliação sobre o uso da participação democrática no estilo materno $\left(, 736^{* *}, p=0,006\right)$. E ainda, quanto mais o pai referiu o uso da participação democrática por sua esposa, mais ele também referiu utilizar-se deste fator $\left(, 809^{* *}, \mathrm{p}=0,001\right)$. Quanto mais o pai referiu que sua esposa se utiliza da paciência/respeito, mais referiu também o uso dela da participação democrática $\left(, 802^{* *}, \mathrm{p}=0,002\right)$, bem como o uso da participação democrática por ele $\left(, 724^{* *}, \mathrm{p}=0,008\right)$.

É interessante observar que o estilo democrático paterno se relaciona com as percepções dele sobre o estilo democrático materno $\left(, 750^{* *}, \mathrm{p}=0,005\right)$, o que não acontece com o estilo democrático materno (mãe falando sobre si mesma).

\section{Correlações entre os fatores do estilo autoritário}

O estilo autoritário foi o único em que apareceram fortes correlações entre o que cada um (pai e mãe) relata sobre si e sobre o parceiro, especialmente com relação aos fatores: castigo físico e estratégia punitiva. Quanto mais a mãe referiu fazer uso de castigo físico $\left(, 749^{* *}, \mathrm{p}=0,005\right)$; de estratégia punitiva $\left(, 716^{* *}, \mathrm{p}\right.$ $=0,009)$ e diretividade excessiva $\left(, 830^{* *}, \mathrm{p}=0,001\right)$, mais ela também referiu uso destes fatores no estilo do companheiro. E quanto mais o pai referiu uso de castigo físico $\left(, 709^{* *}, p=0,010\right)$ e estratégia punitiva $\left(, 754^{* *}, p=0,005\right)$, mais fez referência a estes fatores no estilo materno. E ainda, quanto mais o pai relatou uso de castigo físico no seu próprio estilo, mais a mãe também relatou uso de castigo físico em seu próprio estilo $\left(, 860^{* *}, \mathrm{p}<0,001\right)$.

Diferente do que ocorre com o estilo democrático-recíproco, o estilo autoritário apresenta relações entre estilo materno e paterno, especialmente na avaliação da mãe. Quanto mais ela refere fazer uso do estilo autoritário, mais faz esta referência sobre seu esposo também $\left(, 830^{* *}, p=0,001\right)$. Aqui se evidencia a recursividade do uso do estilo autoritário pelo casal, em especial nos fatores 
castigo físico e estratégia punitiva. Ou seja, há indícios de que o comportamento punitivo de um influencia o comportamento punitivo do outro, reforçando-o.

\section{Considerações sobre os estilos permissivo e autoritário}

A falta de firmeza (fator do estilo permissivo) está representada no questionário por quatro itens, dentre eles: Eu cedo quando o meu filho faz birra; e Digo ao meu filho que vou castigá-lo e depois não cumpro. É interessante observar que a falta de firmeza mostrou correlações positivas fortes e moderadas com todos os fatores do estilo autoritário, tanto na avaliação do pai, como da mãe. A falta de firmeza materna, na avaliação da mãe, mostrou-se fortemente correlacionada com hostilidade verbal materna $\left(, 752^{* *}, p=0,005\right)$; castigo físico materno $\left(, 712^{* *}, p=0,009\right)$; e castigo físico paterno $\left(, 855^{* *}, \mathrm{p}<0,001\right)$. E moderadamente correlacionada com hostilidade verbal paterna $\left(, 648^{*}, \mathrm{p}=0,023\right)$; estratégia punitiva paterna $\left(, 619^{*}, \mathrm{p}=0,032\right)$; e diretividade excessiva materna $\left(, 675^{*}, p=0,016\right)$ e paterna $\left(, 590^{*}, p=0,043\right)$. A falta de firmeza relatada pela mãe (falando de si), também se mostrou fortemente correlacionada com o relato paterno de uso de castigo físico por parte dele $\left(, 737^{* *}, \mathrm{p}=0,006\right)$. E quanto mais a mãe refere falta de firmeza paterna, mais o pai refere uso de estratégia punitiva pela mãe $\left(, 655^{*}, \mathrm{p}=0,021\right)$. O uso de estratégia punitiva pelo pai (relatado por ele próprio) está relacionado à falta de firmeza materna identificada por ele $\left(, 588^{*}, \mathrm{p}=0,044\right)$, bem como, à sua própria falta de firmeza (também identificada por ele) $\left(, 590^{*}, \mathrm{p}=0,044\right)$.

Há, ainda, uma correlação forte e negativa entre a falta de firmeza do pai (relatada por ele próprio) e a paciência e respeito no estilo parental paterno (relatado pela mãe) $\left(-, 727^{* *}, \mathrm{p}=0,007\right)$. Quer dizer, quanto mais o pai relata falta de firmeza em si, menos a mãe refere paciência e respeito no estilo paterno.

Os resultados indicam que a falta de firmeza (fator do estilo permissivo), tanto no relato do pai quanto da mãe, está correlacionada positivamente com fatores do estilo autoritário. Parece haver um "mecanismo compensatório", uma "complementaridade" entre falta de firmeza e uso de castigo físico, de estratégia punitiva e de hostilidade verbal, verificada dentro do estilo individual, como também no interjogo dos estilos de ambos.

\section{Relação coparental e estilo parental democrático-recíproco}

Apenas a avaliação materna sobre a relação coparental apresentou correlações com fatores do estilo democrático. Quanto mais a mãe refere endossar a parentalidade do parceiro, mais ela também refere que ele faz uso do estilo democrático-recíproco $\left(, 711^{* *}, \mathrm{p}=0,010\right)$. Especificamente nos fatores: calor e 
envolvimento $\left(, 757^{* *}, \mathrm{p}=0,004\right)$; estímulo ao raciocínio $\left(, 725^{* *}, \mathrm{p}=0,008\right)$; e paciência e respeito $\left(, 638^{*}, \mathrm{p}=0,026\right)$.

\section{Relação coparental e estilo autoritário}

Entre a relação coparental e estilo autoritário destacam-se as correlações entre a sabotagem coparental e endossamento da parentalidade referidos pelo pai; e satisfação com a divisão do trabalho coparental referida pela mãe com o uso da estratégia punitiva por ambos.

Quanto mais o pai refere se sentir sabotado na relação coparental, mais ele refere fazer uso de estratégia punitiva $\left(, 701^{*}, \mathrm{p}=0,011\right)$, e também mais ele refere uso de estratégia punitiva pela esposa $\left(, 739^{* *}, p=0,006\right)$. O uso de estratégia punitiva pela mãe, segundo relato do pai, mostrou, ainda, correlação forte e negativa com a validação (endossamento) da parentalidade materna por ele $\left(-, 712^{* *}, p=0,009\right)$. Ou seja, quanto mais o pai afirma endossar a parentalidade da mãe, menos ele observa que ela se utiliza de estratégias punitivas no seu estilo parental.

Já na avaliação da relação coparental pela mãe, é a sua satisfação com relação à divisão do trabalho coparental que se mostra negativamente relacionada ao uso da estratégia punitiva. Quanto mais ela refere se sentir satisfeita com a divisão do trabalho, menos ela refere fazer uso de estratégia punitiva $\left(-, 720^{* *}, \mathrm{p}=, 008\right) \mathrm{e}$ menos ela refere uso de estratégia punitiva pelo companheiro $\left(-, 821^{* *}, \mathrm{p}=, 001\right)$.

\section{Relação coparental e estilo permissivo}

Entre a coparentalidade e o estilo permissivo são evidenciados os fatores sabotagem coparental e falta de firmeza, no relato de ambos (pais e mães). Quanto mais o pai refere se sentir sabotado pela sua esposa, mais ele também refere o estilo permissivo dela $\left(, 639^{*}, p=0,025\right)$ e seu $\left(, 712^{* *}, p=0,009\right)$. Especificamente, ele refere haver maior "falta de firmeza" no estilo de sua esposa $\left(, 583^{*}, \mathrm{p}=0,047\right)$ e também no seu próprio estilo $\left(, 583^{*}, \mathrm{p}=0,047\right)$. A falta de firmeza paterna, referida pelo próprio pai, também se mostrou moderadamente relacionada com a sua referência sobre a exposição da criança ao conflito $\left(, 655^{*}\right.$, $p=0,021)$. Quanto mais o pai refere falta de firmeza em seu estilo, mais refere exposição da criança ao conflito coparental.

Especificamente, a referência materna sobre sabotagem coparental por parte do esposo apresentou correlação forte e positiva com a falta de firmeza paterna, referida por ele próprio $\left(739^{* *}, \mathrm{p}=0,006\right)$. E ainda, quanto mais a mãe refere o estilo permissivo em seu esposo, menos ela refere satisfação com a divisão do trabalho coparental $\left(-, 592^{*}, \mathrm{p}=0,042\right)$. 


\section{Discussão}

As correlações entre as dimensões dos estilos parentais entre si e destes com as dimensões da coparentalidade evidenciam a recursividade entre os subsistemas parental (estilos materno e paterno) e coparental. Tomando como ponto de partida os estilos parentais, viu-se que as relações são dinâmicas e as categorias conceituais criadas para defini-las e distingui-las teoricamente não são estanques nem excludentes na prática. Ou seja, os estilos parentais são claramente definidos e são teoricamente distintos entre si, mas na prática, eles coexistem. As análises correlacionais mostraram, por exemplo, que no estilo permissivo há um recorrente uso de práticas autoritárias.

O estilo democrático paterno se relacionou com as percepções dele sobre o estilo democrático materno, ou seja, quanto mais o pai refere fazer uso do estilo democrático, mais faz esta referência sobre sua esposa e vice-versa. Esta relação não acontece com o estilo democrático materno (mãe falando de si), indicando que o estilo democrático da mãe não se relaciona ao estilo paterno (referido por ele ou ao que ela observa no estilo do esposo).

A validação (endossamento) da parentalidade do pai, pela sua esposa, mostrou ser um importante fator da coparentalidade relacionado ao uso do estilo democrático por ele. Quanto mais a mãe refere endossar a parentalidade do parceiro coparental, mais ela refere também que ele faz uso do estilo democrático-recíproco. Especificamente nos fatores: calor/envolvimento; estímulo ao raciocínio; e paciência/respeito.

É possível levantar algumas hipóteses sistêmicas para compreender estes resultados. Por um lado, eles podem indicar uma influência materna na parentalidade do pai, semelhante à descrita na literatura. Estudos evidenciam que o engajamento paterno está relacionado ao engajamento materno, mas não vice-versa; e ainda, que o engajamento materno não apresenta correlações com o relacionamento conjugal, enquanto que o paterno tende a aumentar de acordo com a qualidade do relacionamento com a companheira. (BOSSARDI, 2011). Resultados semelhantes são apresentados por Schoppe-Sullivan et al. (2008), sugerindo que as mães podem moldar o envolvimento paterno através de suas atitudes de crítica ou encorajamento, e que o envolvimento traz repercussões para a qualidade da sua parentalidade.

Assim, a influência materna na parentalidade do pai é evidente, contudo, as relações não são unidirecionais, de forma que os resultados encontrados podem indicar uma relação recursiva, no sentido de que: quanto mais a mãe observa o uso do estilo democrático por seu esposo, mais ela endossa a sua parentalidade, 
reforçando-a. Esta recursividade foi apontada no estudo de Bossardi (2011) ao analisar as especificidades do engajamento materno e paterno e a dinâmica entre eles. Por exemplo, quando a mãe se engaja em jogos físicos (mais realizado pelo pai), o pai aumenta o engajamento em cuidados básicos (mais realizado pela mãe). E quanto mais a mãe se engaja nas funções compartilhadas (tarefas de casa, evocações e abertura ao mundo) mais o pai também se engaja nestas tarefas. E ainda, quando o pai realiza mais jogos físicos com a criança, mais a mãe tende a avaliar positivamente a qualidade do relacionamento conjugal. E o pai tende a se envolver mais em jogos físicos e em cuidados básicos quanto mais positivamente avalia a qualidade do seu relacionamento com a companheira.

A falta de firmeza, fator do estilo permissivo, referida tanto pelo pai como pela mãe (a respeito de si e do cônjuge), apresentou correlações com todos os fatores do estilo autoritário. Quanto mais eles referem a falta de firmeza em si ou no parceiro, mais eles referem utilizar-se de castigos físicos, hostilidade verbal e, especialmente, da estratégia punitiva com a criança. E quando se amplia a análise para as relações entre estilos parentais e coparentalidade, destaca-se que a sabotagem coparental, referida tanto pelo pai como pela mãe, relaciona-se à falta de firmeza. Quanto mais a mãe refere haver sabotagem coparental por parte do esposo, mais ela refere a falta de firmeza no estilo parental dele. E quanto mais o pai refere sentir-se sabotado pela esposa, mais ele refere a falta de firmeza em si e na esposa e mais ele também refere o uso de estratégia punitiva por ambos. Em contrapartida, quanto mais o pai referiu endossar a parentalidade da esposa, menos ele referiu o uso da estratégia punitiva no estilo materno. E o endossamento da parentalidade paterna por parte da esposa relaciona-se, como mencionado, a vários fatores do estilo democrático por parte do pai.

Estes resultados corroboram e contribuem para a ampliação da compreensão dos estudos que evidenciaram o potencial protetivo do suporte coparental para o desenvolvimento infantil. Scott (2009) relatou que o suporte coparental e a satisfação parental são positivamente relacionados entre si e ambos, negativamente relacionados com problemas de comportamento das crianças. Schoppe-Sullivan et al. (2009) verificaram que o suporte coparental moderou longitudinalmente a relação entre controle das crianças e relato dos pais sobre seus problemas de comportamentos de externalização. Kolak e Volling (2013) destacaram, ainda, a importância do suporte coparental como fator protetivo para o ajustamento do filho primogênito, no nascimento do segundo filho. Em contrapartida, a sabotagem coparental, segundo Leroy et al. (2013), mostra uma relação positiva com os problemas de ajustamento infantil, em especial, a sabotagem referida pelos pais.

O conflito coparental sobre questões gerais relativas à criança também mostra relação significativa com problemas infantil de internalização/externali- 
zação. (BARZEL; REID, 2011). A exposição da criança ao conflito é um fator de particular interesse e diz respeito à capacidade do casal em gerenciar as relações familiares (ao preservar ou expor os filhos aos conflitos entre eles). As análises mostraram que a mãe relata maior exposição da criança ao conflito quanto mais o pai refere sabotagem coparental. E a referência paterna de exposição da criança ao conflito se relacionou positivamente à sua autorreferência de falta de firmeza no estilo parental e negativamente à sua avaliação de proximidade coparental. E ainda, quanto mais o pai referiu acordo coparental, menos ambos referiram exposição da criança ao conflito.

Por fim, a falta de firmeza paterna referida pela mãe relaciona-se à sua satisfação com relação à divisão do trabalho coparental e uso de estratégia punitiva. Quanto menos a mãe refere falta de firmeza no estilo do esposo, mais ela refere satisfação com a divisão do trabalho coparental; e quanto mais ela se diz satisfeita com a divisão do trabalho, menos ela refere uso da estratégia punitiva com a criança, por ambos.

\section{Considerações finais}

Os estudos sobre estilos parentais, de forma geral, caracterizam o estilo predominante e avaliam as repercussões de cada estilo no desenvolvimento da criança. O presente estudo buscou contribuir com a ampliação da compreensão de como se dá a relação do uso de diferentes estratégias parentais pelo pai e pela mãe, a partir da sua autopercepção e o que cada um percebe da relação do outro com a criança. E ainda, como se dá a relação das práticas e do estilo parental de cada um com fatores da relação coparental.

Ao identificar as peculiaridades do uso dos diferentes estilos e quais os fatores relacionados a eles no interjogo das relações parentais e coparentais, este estudo permite a identificação de fatores de risco e fatores potencialmente estratégicos na promoção de relações familiares mais saudáveis e promotoras do desenvolvimento das crianças e suas famílias. Destaca-se a relação da falta de firmeza parental com o uso de estratégias punitivas com as crianças; e de ambos com a sabotagem coparental. E a relação do endossamento da parentalidade do parceiro com estilo democrático paterno e menor uso de estratégia punitiva pela mãe.

Assim, a compreensão do interjogo das relações parentais e coparentais permite subsidiar e qualificar as intervenções psicológicas e psicoeducativas com 
as famílias, no âmbito individual e grupal, em diversos contextos: educacional, em serviços de saúde e de assistência social.

Este estudo teve como principal limitação o número de participantes, que inviabilizou a utilização de análises estatísticas mais sofisticadas que apontassem a direção das relações entre as variáveis, identificando fatores moderadores e mediadores das diferentes relações. A partir das contribuições e das limitações deste estudo surgem inúmeras direções para pesquisas futuras. Dentre elas, a inclusão de fatores que não foram contemplados nesta pesquisa, como a conjugalidade, a rede de suporte social da família, além de análises específicas no que se refere às correlações entre as variáveis estudadas e as variáveis sociodemográficas.

Destaca-se, ainda, a importância do desenvolvimento de estudos de validação de instrumentos para a população brasileira. No levantamento bibliográfico realizado não foram encontrados instrumentos que avaliam a coparentalidade construídos no Brasil, ou adaptados e validados para a população brasileira. Pesquisadores portugueses (LAMELA; CASTRO; FIGUEIREDO, 2013; LAMELA et al., 2015) têm realizado adaptações e validação de instrumentos americanos para a sua população, e estes - pela proximidade da língua e mesmo da cultura em algumas regiões do Brasil - podem ser um ponto de partida para estudos de adaptação/validação de instrumentos para a população brasileira, o que traria grande contribuição para o avanço das pesquisas científicas nesta área.

\section{REFERÊNCIAS}

ABIDIN, R.; BRUNNER, J. F. Development of a Parenting Alliance Inventory. Journal of Clinical and Child Psychology, v. 24, n 1, p. 31-40, 1995.

ACHENBACH, T. M. Manual for the Child Behavior Checklist/4-18 and 1991 profile. Burlington, VT: University of Vermont, 1991.

ALVARENGA, P.; PICCININI, C. Práticas educativas e problemas de comportamento em pré-escolares. Psicologia Reflexão e Crítica, v. 14, n. 3, p. 449-460, 2001.

ASSOCIAÇÃO BRASILEIRA DE PESQUISA E MERCADO. Critério de Classificação Econômica Brasil. 2011. Disponível em: <www.abep.og>. Acesso em: 10 dez. 2011.

BARZEL, M.; REID, G. J. Coparenting in relation to children's psychosocial and diabetesspecific adjustment. J. Pediatr. Psychol., v. 36, n. 5, p. 618-29, Jun. 2011.

BAUMRIND, D. Effects of authoritative control on child behavior. Child Development, v. 37, p. 887-907, 1966. 
BAUMRIND, D. The Influence of parenting style on adolescent competence and substance use. Journal of Early Adolescence, v. 11, n. 1, p. 56-95, 1991.

BEM, L. A. de; WAGNER, A. Reflexões sobre a construção da parentalidade e o uso de estratégias educativas em famílias de baixo nível socioeconômico. Psicologia em Estudo, Maringá, v. 11, n. 1, abr. 2006.

BONDS, D. D.; GONDOLI, D. M. Examining the process by which marital adjustment affects maternal warmth: the role of coparenting support as a mediator. J Fam Psychol, v. 21, n. 2, p. 288-96, Jun. 2007.

BORDIN, I. A. S.; MARI, J. J.; CAEIRO, M. F. Validação da versão brasileira do Child Behavior Checklist [CBCL] - Inventário de comportamento da infância e da adolescência: Dados preliminares. Revista $A B P-A P A L$, v. 17, n. 2, p. 55-66, 1995.

BOSSARDI, C. N. Relação do engajamento parental e conflito conjugal no investimento com os filhos. Dissertação (Mestrado em Psicologia) - Programa de Pós-Graduação em Psicologia, Universidade Federal de Santa Catarina, Florianópolis, 2011.

CARVAlHO, M. C. N.; GOMIDE, P. I. C. Práticas educativas parentais em famílias de adolescentes em conflito com a lei. Estudos de Psicologia, Campinas, v. 22, n. 3, p. 263-274, 2005.

COSTA, F. T. da; TEIXEIRA, M. A. P.; GOMES, W. B. Responsividade e exigência: duas escalas para avaliar estilos parentais. Psicologia Reflexão e Crítica, v. 13, n. 3, p. 465-473, 2000.

DANCEY, C. P.; REIDY, J. Estatística sem matemática para Psicologia. Porto Alegre: Penso, 2013.

FEINBERG, M. E. Coparenting and the transition to parenthood: a framework for prevention. Clin. Child Fam. Psychol. Rev., v. 5, n. 3, p. 173-95, Sep. 2002.

FEINBERG, M. E. The Internal Structure and Ecological Context of Coparenting: a Framework for Research and Intervention. Parenting: Science and Practice, v. 3, n. 2, p. $95-131,2003$.

FEINBERG, M. E.; BROWN, L. D.; KAN, M. L. A multi-domain self-report measure of coparenting. Parenting: Science and Practice, v. 12, n. 1, p. 1-21, 2012.

KARREMAN, A. et al. Parenting, coparenting, and effortful control in preschoolers. $J$ Fam Psychol, v. 22, n. 1, p. 30-40, Feb. 2008.

KOBARG, A. P. R.; VIEIRA, V.; VIEIRA, M. L. Validação da Escala de Lembranças sobre Práticas Parentais (Embu). Avaliação Psicológica, Porto Alegre, v. 9, n. 1, 2010.

KOLAK, A. M.; VOLLING, B. L. Coparenting moderates the association between firstborn children's temperament and problem behavior across the transition to siblinghood. Journal of Family Psychology, v. 27, n. 3, p. 355-364, 2013. 
BÖING, E.; CREPALDI, M. A. Relação pais e filhos: compreendendo o interjogo das relações...

LAMELA, D.; CASTRO, M.; FIGUEIREDO, B. Medida da aliança parental: validação portuguesa e construção de uma versão reduzida. Rev. psiquiatr. clín., São Paulo, v. 40, n. 6, p. 215-219, 2013.

LAMELA, D.; FIGUEIREDO, B.; BASTOS, A.; FEINBERG, M. Typologies of post-divorce coparenting and parental well-being, parenting quality and children's psychological adjustment. Child Psychiatry \& Human Development, v. XX, p. 1-15, 2015.

LEROY, M. et al. Longitudinal links between early coparenting and infant behaviour problems. Early Child Development and Care, v. 183, n. 3-4, p. 360-377, 2013.

MACARINI, S. M. et al. Práticas parentais: uma revisão da literatura brasileira. Arquivos Brasileiros de Psicologia, v. 62, n. 1, 2010.

MACCOBY, E. E.; MARTIN, J. Socialization in the context of the family: parentchild interaction. In: HETHERINGTON, E. M.; MUSSEN, P. H. (Ed.). Handbook of child psychology. New York: Wiley, 1983. v. 4: Socialization, personality and social development. p. 1-101.

OLIVEIRA, E. A. et al. Estilos parentais autoritário e democrático-recíproco intergeracionais, conflito conjugal e comportamentos de externalização e internalização. Psicologia Reflexão e Crítica, v. 15, p. 1-11, 2002.

PEDRO, M. F.; CARAPITO, E.; RIBEIRO, T. Parenting Styles and Dimensions Questionnaire. Psicologia Reflexão e Crítica, v. 28, n. 2, p. 302-312, 2015. Versão em Português.

PICCININI, C. A. et al. Práticas educativas de pais e mães de crianças aos 18 meses de idade. Psicologia: Teoria e Pesquisa, v. 23, n. 4, p. 369-378, 2007.

ROBINSON, C. et al. The Parenting Styles and Dimension Questionnaire (PSQD). In: PERLMUTTER, B. F.; TOULIATOS, J.; HOLDEN, G. W. (Ed.). Handbook of Family Measurement Techniques. Thousand Oaks, CA: Sage, 2001. v. 3: Instruments \& Index. p. 319-321.

SCHOPPE-SULLIVAN, S. J. et al. Maternal gatekeeping, coparenting quality, and fathering behavior in families with infants. J Fam Psychol, v. 22, n. 3, p. 389-98, Jun. 2008.

SCHOPPE-SULLIVAN, S. J. et al. Coparenting behavior moderates longitudinal relations between effortful control and preschool children's externalizing behavior. J Child Psychol Psychiatry, v. 50, n. 6, p. 698-706, Jun. 2009.

SCOTT, S. L. Predicting Children's Emotional and Behavioral Functioning: an Examination of Coparenting and Parental Satisfaction. Thesis - University of Central Florida, 2009.

TREMBLAY, R. E. The development of aggressive behavior during childhood: What have we learned in the past century? International Journal of Behavioral Development, v. 24 , p. $129-141,2000$. 
BÖING, E.; CREPALDI, M. A. Relação pais e filhos: compreendendo o interjogo das relações...

VAN EGEREN, L.; HAWKINS, D. Coming to terms with coparenting: Implications of definition and measurement. Journal of Adult Development, v. 11, p. 165-178, 2004.

WEBER, L. N. D. et al. Identificação de estilos parentais: o ponto de vista dos pais e dos filhos. Psicologia Reflexão e Crítica, v. 17, n. 3, p. 323-331, 2004.

WEBER, L. N. D. et al. Continuidade dos estilos parentais através das gerações: transmissão intergeracional de estilos parentais. Paidéia, Ribeirão Preto, v. 16, n. 35, 2006.

Texto recebido em 04 de janeiro de 2016. Texto aprovado em 04 de janeiro de 2016. 
